\title{
EFEITO DE SUBSTÂNCIAS HÚMICAS NA CINÉTICA DE ABSORÇÃO DE POTÁSSIO, CRESCIMENTO DE PLANTAS E CONCENTRAÇÃO DE NUTRIENTES EM Phaseolus vulgaris L. ${ }^{(1)}$
}

\author{
Carla Machado da Rosa ${ }^{(2)}$, Rosa Maria Vargas Castilhos ${ }^{(3)}$, Ledemar \\ Carlos Vahl ${ }^{(3)}$, Danilo Dufech Castilhos ${ }^{(3)}$, Luiz Fernando Spinelli \\ Pinto $^{(3)}$, Elisandra Solange Oliveira ${ }^{(4)}$ \& Otávio dos Anjos Leal ${ }^{(5)}$
}

\section{RESUMO}

As substâncias húmicas podem influenciar direta ou indiretamente o metabolismo das plantas, alterando assim o seu crescimento. O objetivo deste trabalho foi avaliar o efeito de substâncias húmicas (SH) no crescimento e na concentração de nutrientes em plantas de feijão (Phaseolus vulgaris, L.) e nos parâmetros cinéticos de absorção de K. O experimento foi realizado em bancada de laboratório, com luz artificial. As plantas cresceram em vasos contendo solução nutritiva completa acrescida de cinco doses $\left(0 ; 2,5 ; 5 ; 10 ;\right.$ e $20 \mathrm{mg} \mathrm{L}^{-1}$ de C) de SH solúveis em meio alcalino (ácido húmico + ácido fúlvico), extraídos de amostra de carvão mineral da mina de Candiota, RS, da Companhia Riograndense de Mineração, num delineamento completamente ao acaso, com três repetições. Aos 28 dias de cultivo, foram avaliados parâmetros cinéticos de absorção de $\mathrm{K}$, massa da parte aérea e da raiz seca, teores de $\mathrm{N}, \mathrm{P}, \mathrm{K}, \mathrm{Ca}$ e $\mathrm{Mg}$ no tecido da parte área e as características morfológicas de raízes (comprimento, área e raio). Os resultados evidenciaram que a adição de SH extraída de carvão mineral estimulou o crescimento do feijão e afetou a cinética de absorção de $K$. A produção de massa da parte aérea seca das plantas mostrou resposta quadrática à adição de substâncias húmicas, atingindo valor máximo na dose equivalente a $11 \mathrm{mg} \mathrm{L}^{-1} \mathrm{de}$

\footnotetext{
(1) Recebido para publicação em outubro de 2008 e aprovado em maio de 2009.

(2) Estudante do Programa de Pós Graduação em Agronomia, área de concentração Solos, Universidade Federal de Pelotas UFPel. Campus Universitário, CEP 96001-970 Pelotas (RS). E-mail: carlamrosa@yahoo.com.br

(3) Professor do Departamento de Solos da Faculdade de Agronomia “Eliseu Maciel”, UFPel. E-mails: rosamvc@ufpel.edu.br; danilodc@ufpel.edu.br; lcvahl@ufpel.edu.br; lfspin@ufpel.tche.br

(4) Estudante do Programa de Pós Graduação em Ciência do Solo, Universidade Federal do Rio Grande do Sul - UFRGS. Av. Bento Gonçalves 7712, CEP 91540-000 Porto Alegre (RS). E-mail: elisandrao@pop.com.br

(5) Bolsista de iniciação científica do Departamento de Solos da Faculdade de Agronomia "Eliseu Maciel”, UFPel. E-mail: oleal@ibest.com.br
} 
C, enquanto a massa das raízes secas aumentou linearmente em até $41 \%$, com as doses testadas. As características morfológicas de raiz e o estado nutricional das plantas não foram significativamente afetados pelas SH. Os parâmetros cinéticos de absorção de K, Imáx, Cmín e Km, decresceram linearmente com o aumento das doses de $\mathrm{SH}$, causando redução na taxa de absorção de $K$ nas concentrações deste nutriente na solução superiores a $10 \mu \mathrm{mol} \mathrm{L} \mathrm{L}^{-1}$.

Termos de indexação: Michaelis-Menten, humato de carvão, morfologia radicular, absorção de $\mathrm{K}^{+}$.

\title{
SUMMARY: EFFECT OF HUMIC-LIKE SUBSTANCES ON POTASSIUM UPTAKE KINETICS, PLANT GROWTH AND NUTRIENT CONCENTRATION IN Phaseolus vulgaris $L$.
}

\begin{abstract}
Humic substances can influence plant metabolism direct or indirectly, thus modifying its growth. The objective of this study was to evaluate the effect of humic-like substances (HS) on kinetics of K uptake, nutrient concentration and growth of common bean (Phaseolus vulgaris, L.). The experiment was performed on a laboratory bench with controlled light conditions. Plants were grown in pots with complete nutrient solution enriched with five levels $(0 ; 2.5 ; 5 ; 10$ and $20 \mathrm{mg} \mathrm{L}^{-1}$ of C) of alkaline soluble humic-like substances (fulvic and humic acids), extracted from mineral charcoal samples from the Candiota mine (Companhia Riograndense de Mineração), in the State of Rio Grande do Sul, Brazil. The experiment was set up in a randomized design, with three replications. After 28 days of plant growth, kinetics parameters of K uptake, shoot and root dry weight, shoot tissue concentration of nutrients (N, $P, K, C a$ and $\mathrm{Mg}$ ) and root morphological parameters (length, area and radius) were evaluated. The results showed that the application of charcoal-extracted humic substances stimulated common bean growth and influenced the kinetics parameters of K uptake. A quadratic response to HS was observed in shoot dry weight, which reached the highest values at $11 \mathrm{mg} \mathrm{L}^{-1}$ of $C$, whereas root dry mass increased linearly up to $41 \%$ along the increasing HS concentration in solution. Root morphological parameters and nutritional conditions of plants were not significantly affected by HS. The kinetic parameters of K uptake, Imax, Cmin and Km, decreased with increasing HS concentration, causing reduction in K influx when the Kconcentration in solution exceeded $10 \mu \mathrm{mol} \mathrm{L}^{-1}$
\end{abstract}

Index terms: charcoal humate, common bean, root morphology, potassium influx.

\section{INTRODUÇÃO}

As substâncias húmicas (SH), compostas de ácidos húmicos, ácidos fúlvicos e humina, são os principais componentes da matéria orgânica do solo (85 a $90 \%$ ) e originam-se a partir de transformações bioquímicas de compostos como lignina, celulose, hemicelulose, açúcares, aminoácidos, etc. (Silva \& Mendonça, 2007). Quimicamente a constituição do material de origem da matéria orgânica do solo é semelhante à do carvão, o que significa que esse elemento também pode conter substâncias húmicas. Segundo Silva et al. (1999), os carvões extraídos de diferentes minas do Estado do Rio Grande do Sul possuem, em sua composição, de 10 a 26 \% de substâncias húmicas, constituindo uma fonte barata e não poluente de $\mathrm{SH}$, que podem desempenhar vários papéis benéficos às plantas.

Neste trabalho, utilizou-se um carvão mineral do tipo betuminoso, proveniente de uma camada não minerada do perfil geológico da mina de Candiota, da
Companhia Riograndense de Mineração (CRM), com espessura variável de 0,60 a $0,90 \mathrm{~cm}$, denominada banco louco (BL) (Silva \& Kalkreuth, 2005). Esta camada comumente é retirada com o material de cobertura das camadas mineradas e utilizada posteriormente na regeneração dos solos das áreas mineradas, podendo causar sérios problemas de acidificação, pela presença da pirita $\left(\mathrm{FeS}_{2}\right)$, dificultando a revegetação das áreas reconstruídas (Pinto \& Kampf, 2002). Dessa forma, a separação do carvão desta camada (BL) e seu aproveitamento através da extração e utilização agrícola de $\mathrm{SH}$ podem representar uma alternativa viável e de interesse, especialmente do ponto de vista ambiental.

Os efeitos das substâncias húmicas nas plantas estão relacionados com o aumento na absorção de nutrientes, devido à influência na permeabilidade da membrana celular e ao poder quelante, bem como à fotossíntese, à formação de ATP, aminoácidos e proteínas (Vaughan et al., 1985). As substâncias 
húmicas alteram diretamente o metabolismo bioquímico das plantas e, por consequência, podem influir no seu crescimento e desenvolvimento.

O efeito das substâncias húmicas não é fácil de ser explicado, devido à natureza complexa ainda pouco conhecida dessas substâncias. Há substâncias húmicas com características muito diferentes, devido à origem do material, ao método de extração e até mesmo pelas diferentes concentrações em que se encontram. Esses efeitos também podem diferir entre espécies vegetais, que podem responder diferentemente em cada estádio de desenvolvimento (Santos \& Camargo, 1999).

O estabelecimento de um modelo estrutural para as substâncias húmicas é tema ainda controverso. O modelo mais aceito é de que as substâncias húmicas são macromoléculas que têm sua conformação variável de acordo com as condições do meio (Stevenson, 1994; Santos \& Camargo, 1999). Este modelo explica macroscopicamente as principais interações das substâncias húmicas, como a capacidade de adsorção e complexação de íons e interação com minerais do solo. No entanto, Picollo (2002) propôs a teoria de que as substâncias húmicas são formadas por arranjo supraestrutural de pequenas moléculas orgânicas através de forças de interação fraca. Este modelo é bastante útil para descrever o comportamento ambiental das substâncias húmicas, bem como os efeitos que elas têm sobre o metabolismo das plantas. A interação planta-microrganismos pode alterar a estrutura e a conformação das substâncias húmicas, e pequenas unidades portadoras de bioatividade podem estimular o crescimento e o metabolismo dos organismos.

A ação direta das substâncias húmicas sobre o metabolismo e o crescimento das plantas tem sido atribuída principalmente à ação das substâncias húmicas de menor peso molecular, principalmente os ácidos fúvicos (Vaughan et al., 1985; Nardi et al., 2002). A concepção do arranjo supraestrutural das substâncias húmicas preconiza que compostos de reconhecida capacidade de regulação e estimulação do crescimento vegetal (hormônios vegetais, por exemplo) pode estar unidos à supra-estrutura das substâncias húmicas e, assim, podem ser liberados para a solução do solo por uma variação de $\mathrm{pH}$ na rizosfera. Segundo Sposito (1989), as substâncias húmicas possuem propriedades de polifuncionalidade, carga molecular, hidrofilicidades e flexibilidade estrutural, e têm a capacidade de mudar a conformação molecular de acordo com as mudanças de $\mathrm{pH}$, Eh, força iônica e das ligações dos grupamentos funcionais.

O aumento da absorção de nutrientes proporcionado pela presença de substâncias húmicas em solução tem sido atribuído ao aumento da permeabilidade da membrana plasmática por meio da ação das substâncias húmicas e à ativação da $\mathrm{H}^{+}$-ATPase de membrana plasmática (Canellas \& Santos, 2005). As H $\mathrm{H}^{+}$-ATPases (bombas de $\mathrm{H}^{+}$) são enzimas transmembranares capazes de hidrolisar ATP, gerando energia e gradiente eletroquímico que está diretamente envolvido em dois mecanismos fundamentais para o desenvolvimento e crescimento vegetal: (a) energização de sistemas secundários de translocação de íons fundamentais para a absorção de macro e micronutrientes, e (b) aumento da plasticidade da parede celular para possibilitar o processo de crescimento e divisão da célula vegetal (Rodda et al., 2006a). Esse último mecanismo está relacionado com a "teoria do crescimento ácido", que postula que o aumento da extrusão de prótons mediado pela $\mathrm{H}^{+}$-ATPase promove a acidificação do apoplasto, que, por sua vez, ativa enzimas específicas que atuam sobre a parede celular, aumentando sua plasticidade e, consequentemente, permitindo o alongamento da célula (Rayle \& Cleland, 1992). Alguns autores obtiveram resultados positivos no crescimento de plantas (parte aérea e raízes) de aveia, azevém e alface, utilizando doses entre 10 e $25 \mathrm{mg} \mathrm{L}^{-1}$ de C nas substâncias húmicas extraídas de solo, carvão e vermicomposto, respectivamente (Pinton et al., 1992; Silva et al., 2000; Rodda et al., 2006a). Testando humatos isolados de vermicomposto produzidos com esterco bovino e com mistura de bagaço de cana-deaçúcar em plântulas de alface, Rodda et al. (2006a) observaram desenvolvimento radicular significativamente superior ao do controle (sem humato). Esses autores verificaram que os humatos extraídos de esterco de curral e esterco de curral + bagaço de cana-deaçúcar proporcionaram acréscimos de 180 e 190 \% na área radicular, e de 150 e $140 \%$ no comprimento total radicular, respectivamente, em relação ao controle.

Além da influência das substâncias húmicas sobre a absorção de nutrientes, a quantidade absorvida também depende da área superficial de raízes. O estímulo na atividade da $\mathrm{H}^{+}$. ATPase de membrana plasmática pela presença de substâncias húmicas de baixo peso molecular parece favorecer a emissão de pelos radiculares e raízes laterais finas, aumentando assim a área superficial do sistema radicular (Façanha et al., 2002; Canellas \& Santos, 2005). Rodda et al. (2006b), utilizando solução aquosa de humato de vermicomposto de esterco de curral no substrato para produção de mudas de alface, verificaram maior crescimento tanto da parte área como do comprimento do sistema radicular de plântulas de alface, e o efeito foi dependente da concentração do humato na água de irrigação. Os autores observaram que a concentração de $25 \mathrm{mg} \mathrm{L}^{-1}$ de $\mathrm{C}$ de humato proporcionou o maior acréscimo na área radicular.

A taxa de absorção de nutrientes é estimada através de parâmetros cinéticos de absorção, que também podem ser afetados pelas substâncias húmicas Os parâmetros cinéticos são: Imáx, que corresponde à máxima taxa de absorção; Km, concentração do íon na qual se atinge a metade da velocidade máxima de absorção, e o Cmín que corresponde à concentração mínima do íon na solução em que a planta não consegue mais absorvê-lo. Uma combinação de alto valor para Imáx e baixos valores para Km e Cmín, 
juntamente com maior crescimento radicular, seria característica desejável numa espécie, pois representa maior eficiência na absorção do nutriente (Barber, 1995). Costa (2001) observou alterações nos parâmetros cinéticos de absorção de $\mathrm{K}$ e $\mathrm{P}$ em plantas de cebola utilizando substâncias húmicas extraídas de vermicomposto comercial. Cacco et al. (2000) verificaram que frações húmicas de baixo peso molecular aumentaram a taxa de absorção de nitrato. Resultado oposto foi evidenciado para frações húmicas de alto peso molecular.

O objetivo deste trabalho foi avaliar o efeito de substâncias húmicas solúveis extraídas de carvão mineral nos parâmetros cinéticos de absorção de K e no crescimento e na concentração de nutrientes em plantas de feijão.

\section{MATERIAL E MÉTODOS}

O experimento foi conduzido em solução nutritiva no Laboratório de Nutrição e Adubação de plantas, do Departamento de Solos da UFPel, nas seguintes condições: foto período de $12 \mathrm{~h}$ com fornecimento de luz artificial (16.500 lux), composta por 45 lâmpadas amarelas de $100 \mathrm{~W}$ e 45 lâmpadas fluorescentes de 40Watts, distribuídas alternadamente sobre as plantas, a uma altura de $90 \mathrm{~cm}$ da borda superior dos vasos; temperaturas diurnas de $27 \pm 2{ }^{\circ} \mathrm{C}$ e noturnas de $22 \pm 2^{\circ} \mathrm{C}$, medida na superfície dos vasos.

Os tratamentos consistiram de solução nutritiva completa acrescida de cinco doses de substâncias húmicas solúveis (ácido húmico + ácido fúlvico), extraídas de carvão mineral e arranjados num delineamento completamente casualizado, com três repetições. As unidades experimentais constituíram de vasos de PVC com capacidade de $1 \mathrm{~L}$ de solução onde foram cultivadas três plantas de feijão (Phaseolus vulgaris L.), sustentadas com tampas de isopor. Foi instalado um sistema de bombas e mangueiras para fazer a aeração da solução.

O carvão utilizado como matéria-prima para a extração das SH é procedente da mina de Candiota, da Companhia Riograndense de Mineração, RS, e caracterizado como tipo betuminoso, alto volátil C, com alto teor de cinzas, que compõe uma camada não minerada denominada banco loco (BL) (Silva \& Kalkreuth, 2005). De acordo com Silva et al. (1999), que caracterizaram diversos carvões do RS, os carvões da mina de Candiota apresentaram teor médio de $\mathrm{SH}$ de $19 \%(\mathrm{~m} / \mathrm{m})$, com $4,0 \%$ de ácidos húmicos e $2,2 \%$ de ácidos fúlvicos purificados.

A extração das substâncias húmicas solúveis (humato) foi feita com $\mathrm{NaOH} 0,1 \mathrm{~mol} \mathrm{~L}^{-1}$ (relação $1: 10$ ), agitando-se durante $16 \mathrm{~h}$ em temperatura ambiente, com posterior centrifugação $(2500 \mathrm{rpm}$ durante $15 \mathrm{~min}$ ) e filtragem do sobrenadante (Dick et al., 1997). Este procedimento foi repetido por mais três vezes, para que as frações solúveis em meio alcalino (ácido húmico + ácido fúlvico) pudessem ser totalmente extraídas. Os sobrenadantes das três extrações foram reunidos e o excesso de $\mathrm{Na}$ retirado após cinco agitações com resina catiônica IR-120.

O teor de $\mathrm{C}$ da substância húmica solúvel foi determinado por espectroscopia, medindo-se a absorbância a $580 \mathrm{~nm}$, após reação com solução ácida de dicromato de $\mathrm{K} 0,625 \mathrm{~mol} \mathrm{~L}^{-1}$, durante $4 \mathrm{~h}$, a $60^{\circ} \mathrm{C}$, empregando-se curva padrão de D-glucose anidra (Dick et al., 1998). As doses de SH utilizadas foram: 0; 2,5; 5,0; 10 ; e $20 \mathrm{mg} \mathrm{L}^{-1}$ de C, e o volume usado em cada tratamento foi estabelecido com base no seu teor de C.

A concentração de nutrientes na solução nutritiva em mg L ${ }^{-1}$ foi: 78 de K, 24 de $\mathrm{Mg}, 15$ de P, 63 de N, 40 de $\mathrm{Ca}, 32$ de $\mathrm{S}, 5$ de Fe, 0,30 de $\mathrm{Cu}, 0,30$ de $\mathrm{Mn}, 0,1$ de $\mathrm{Zn}, 0,25$ de B e 0,01 de Mo (adaptado de Silva et al., 1999). Durante o cultivo, as soluções acrescidas das substâncias húmicas foram renovadas semanalmente, e o $\mathrm{pH}$ foi verificado a cada três dias e ajustado, quando necessário (variações de $\pm 0,3$ ), para $\mathrm{pH}$ 6,0.

Após 28 dias de cultivo, foram avaliados os parâmetros cinéticos da absorção de K (Imáx, Km e Cmín). Esses foram determinados, em cada tratamento, a partir da diminuição da concentração deste íon na solução nutritiva em função do tempo, conforme método descrito por Claassen \& Barber (1974). Na véspera da medição, as soluções foram trocadas, omitindo-se o K, durante $24 \mathrm{~h}$. No dia da determinação, foram adicionados $75 \mu \mathrm{mol} \mathrm{L}{ }^{-1}$ de $\mathrm{K}$, e alíquotas das soluções $(10 \mathrm{~mL})$ foram coletadas com intervalos regulares de 20 min num total de 24 coletas. $\mathrm{O}$ volume dos vasos foi mantido constante, repondo-se com água destilada a solução retirada. O teor de $\mathrm{K}^{+}$ nas alíquotas foi determinado por fotometria de chama (Tedesco et al., 1995). O ajuste das curvas de depleção de $\mathrm{K}$ e os cálculos dos parâmetros cinéticos foram realizados empregando-se o processo gráfico matemático proposto por Ruiz (1985). A taxa de absorção ou o influxo líquido (Il) foi calculado conforme Claassen \& Barber (1974) pela equação:

$$
\begin{gathered}
\mathrm{Il}\left(\mu \mathrm{mol} \mathrm{g}^{-1} \mathrm{~L}^{-1}\right)=[\text { Imáx }(\text { concentração } \\
\mathrm{K}-\mathrm{Cmín})] / \mathrm{Km}+(\text { concentração } \mathrm{K}-\text { Cmín })
\end{gathered}
$$

Na parte aérea das plantas, foram quantificados a matéria seca, após secagem em estufa a $65^{\circ} \mathrm{C}$ até peso constante, e os teores de $\mathrm{N}, \mathrm{P}, \mathrm{K}, \mathrm{Ca}$ e $\mathrm{Mg}$, segundo método descrito por Tedesco et al. (1995). Nas raízes, foram determinadas as características morfológicas: comprimento (L), estimado pelo método de interseção das quadrículas (Tennant, 1975); raio $(\mathrm{r})$, calculado por $\mathrm{r}=(\mathrm{pu} / \pi \mathrm{L} \cdot \mathrm{L})^{1 / 2}$, considerando peso do material úmido (pu) e comprimento (L); área radicular $(\mathrm{AR})$, calculada a partir da fórmula $\mathrm{AR}=2 . \pi . r . \mathrm{L}$, e peso do material seco.

Os resultados foram submetidos à análise de variância, e, quando significativos, foi feita a regressão polinomial para avaliar os efeitos das doses de 
substâncias húmicas extraídas de carvão sobre as variáveis estudadas, utilizando o sistema de Análise Estatística Winstat (Machado, 2001).

\section{RESULTADOS E DISCUSSÃO}

\section{Crescimento das plantas e teor de nutrientes na parte aérea}

Para as variáveis massa da parte aérea e da raiz seca, a análise de regressão apresentou significância para os efeitos das doses de substâncias húmicas $(\mathrm{p}<0,05)$. A adição de substâncias húmicas aumentou a produção de massa da parte aérea em até $30 \%$ (Figura 1a). Com base no modelo quadrático de regressão ajustado $\left(\hat{y}=4,63+0,30 \mathrm{SH}-0,014 \mathrm{SH}^{2}\right.$, $\mathrm{R}^{2}=0,81^{*}$ ), estimou-se que o rendimento máximo de massa da parte aérea seca foi obtido com a dose de $11 \mathrm{mg} \mathrm{L}^{-1}$ de C.

A massa da raiz seca (Figura 1b) aumentou linearmente até a maior dose de substâncias húmicas testado, sendo $41 \%$ maior que no tratamento sem substâncias húmicas (testemunha). O coeficiente de determinação $\left(R^{2}\right)$ obtido indica que $67 \%$ da variação observada foi atribuída ao efeito dos tratamentos (doses de substâncias húmicas). Esses resultados estão de acordo com os de outros autores que também observaram maior crescimento de raízes de azevém
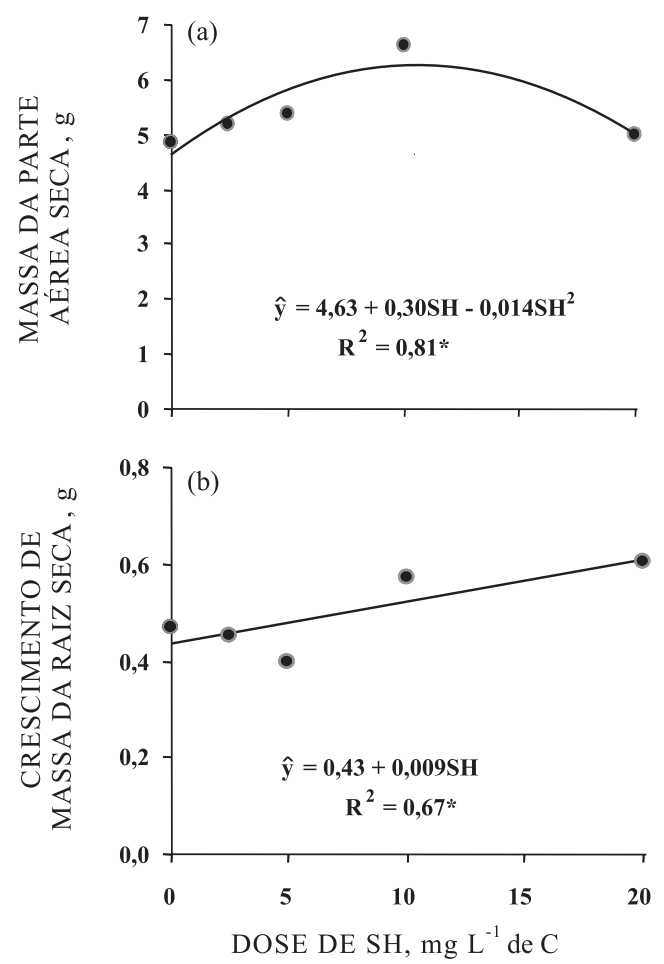

Figura 1. Massas da parte aérea (a) e das raízes secas (b) de plantas de feijão, aos 28 dias, em resposta a doses de substâncias húmicas solúveis (SH) de carvão mineral $(n=3) . *$ significativo a $5 \%$. em solução nutritiva acrescida de substâncias húmicas, em doses entre 10 e $20 \mathrm{mg} \mathrm{L}^{-1}$ de $\mathrm{C}$ (Silva et al., 2000), corroborando as informações da literatura de que as substâncias húmicas influenciam positivamente o crescimento das plantas (Vaughan et al., 1985; Tan, 1998; Nardi et al., 2000a).

Esses resultados podem estar relacionados com a bioatividade das substâncias húmicas, que podem ter efeito auxínico sobre as plantas e com a ativação da $\mathrm{H}^{+}$-ATPase de membrana plasmática. A ativação da $\mathrm{H}^{+}$-ATPase promove aumento do gradiente eletroquímico de $\mathrm{H}^{+}$, provocando a acidificação do apoplasma que leva ao rompimento de ligações da parede celular, promovendo sua elasticidade, o que favorece o crescimento celular (Rayle \& Cleland, 1992; Canellas \& Santos, 2005).

Neste trabalho, não foi observado efeito significativo de substâncias húmicas extraídas de carvão nas seguintes características radiculares: comprimento, área e raio das raízes de feijão (Quadro 1), contrariando outros autores que verificaram efeitos de substâncias húmicas nas características radiculares, quando testadas em outras espécies vegetais. Costa (2001), avaliando o efeito das substâncias húmicas extraídas de vermicomposto comercial no crescimento de cebola, observou aumento de $41 \%$ no comprimento e $22 \%$ na área radicular. Silva et al. (1999) observaram maior crescimento do sistema radicular de plantas de milho na presença de substâncias húmicas de carvão. Parece que tais efeitos variam conforme a origem da substância húmica e a espécie vegetal cultivada.

Somente as concentrações de Mg e P na parte aérea das plantas de feijão foram significativamente afetadas $(\mathrm{p}<0,05)$ pela presença de substâncias húmicas. Para essas variáveis, houve decréscimo até as doses de 9,4 e $11 \mathrm{mg} \mathrm{L}^{-1}$ de $\mathrm{C}$, respectivamente, e aumentando a partir desses valores (Figura 2). As reduções nas concentrações de $\mathrm{Mg}$ e $\mathrm{P}$ observadas podem ser explicadas por um efeito de diluição desses nutrientes, em razão do maior crescimento da parte aérea das

Quadro 1. Características morfológicas radiculares de plantas de feijão, aos 28 dias, em resposta a doses de substâncias húmicas solúveis $(\mathrm{SH})(\mathrm{n}=3)$

\begin{tabular}{lccc}
\hline Tratamento & Comprimento & Área & Raio \\
& $\mathrm{m}$ & $\mathrm{cm}^{2}$ & $\mathrm{x} 10^{-2} \mathrm{~cm}$ \\
& 116 & 1.167 & 1,62 \\
(SN) solução nutritiva & 122 & 1.090 & 1,44 \\
$\mathrm{SN}+\mathrm{SH}\left(2,5 \mathrm{mg} \mathrm{L}^{-1} \mathrm{C}\right)$ & 105 & 995 & 1,51 \\
$\mathrm{SN}+\mathrm{SH}\left(5,0 \mathrm{mg} \mathrm{L}^{-1} \mathrm{C}\right)$ & 128 & 1.063 & 1,32 \\
$\mathrm{SN}+\mathrm{SH}\left(10,0 \mathrm{mg} \mathrm{L}^{-1} \mathrm{C}\right)$ & 127 & 1.222 & 1,54 \\
$\mathrm{SN}+\mathrm{SH}\left(20,0 \mathrm{mg} \mathrm{L}^{-1} \mathrm{C}\right)$ & 120 & 1.107 & 1,49 \\
Média & 20,2 & 17,8 & 10,9 \\
$\mathrm{CV} \%$ & & & \\
\hline
\end{tabular}



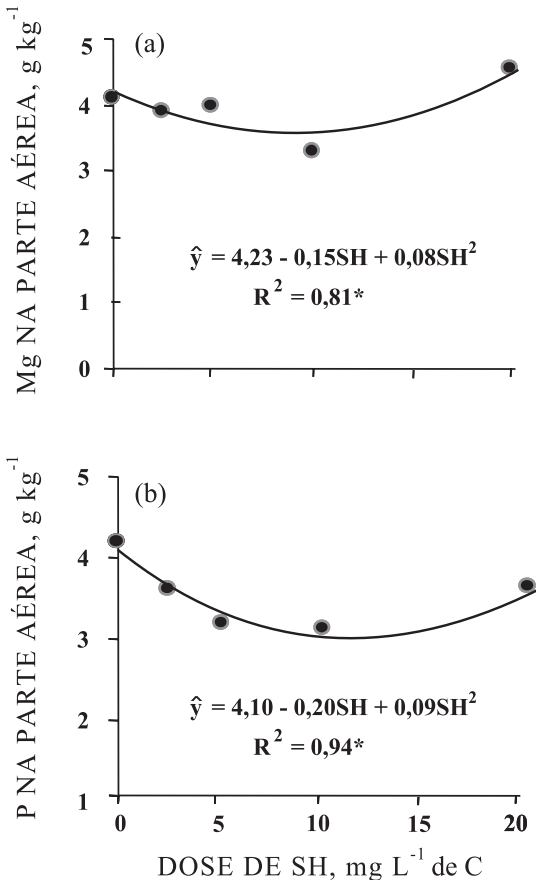

Figura 2. Concentração de $M g$ (a) e $P$ (b) na parte aérea de plantas de feijão, aos 28 dias, em resposta a doses de substâncias húmicas solúveis $(\mathrm{SH})(\mathrm{n}=3) . * \mathrm{e} * *$ significativo a 5 e $1 \%$, respectivamente.

plantas próximo dessas doses (Figura 1a). Os demais nutrientes apresentaram a mesma tendência, porém a regressão não foi significativa $(p>0,05)$. Os teores de $\mathrm{Ca}, \mathrm{K}$ e $\mathrm{N}$ na parte aérea foram em média 12, 26 e $30 \mathrm{~g} \mathrm{~kg}^{-1}$, respectivamente.

Mesmo com decréscimo na concentração de nutrientes na parte aérea das plantas, nas doses intermediárias de substâncias húmicas, o estado nutricional do feijão não foi comprometido, já que as concentrações de N, P, K, Ca, Mg obtidas em todas as doses ficaram dentro das faixas consideradas adequadas para esta espécie (CQFSRS/SC, 2004). De certa forma, este resultado era esperado, uma vez que o trabalho foi realizado em solução completa com suprimento adequado de nutrientes. Resultados semelhantes foram obtidos por Costa (2001), em que a presença de SH não alterou a concentração de macro e micronutrientes na parte aérea da cebola.

\section{Cinética de absorção de $K$}

Os parâmetros cinéticos Imáx, Km e Cmín decresceram linearmente com o aumento das doses de substâncias húmicas (Figura 3). Quanto menor for o Km, maior será a afinidade do íon pelo carregador, uma vez que com menores concentrações se alcança a metade da velocidade máxima de absorção. O Cmín foi o parâmetro que mais diminuiu com o aumento das doses de substâncias húmicas, chegando a reduzir mais de $90 \%$ em relação à testemunha na maior dose
(20 mg L-1 de C). Como o Cmín representa a concentração mínima a partir da qual a planta começa a absorver nutrientes da solução, sua redução sugere que maior poderá ser a adaptabilidade do feijão a ambiente com menor disponibilidade de K. Porém, segundo Anghinoni et al. (1989), valores mais baixos de Imáx indicam menor eficiência de absorção em condições de alta concentração do nutriente na solução. Desse modo, pode-se inferir que, quanto maior a dose de $\mathrm{SH}$, maior será a adaptabilidade do feijão à baixa fertilidade do nutriente, porém, quando submetido a concentrações mais elevadas, a eficiência de absorção de $\mathrm{K}$ será reduzida, mesmo com maior crescimento radicular. Reduções no Cmín de até 50 \% e no Km de até $22 \%$ de $\mathrm{K}$ também foram obtidas em plantas de cebola na presença de substâncias húmicas de vermicomposto comercial, não havendo influência no Imáx (Costa, 2001).

Esses efeitos das SH nos parâmetros cinéticos de absorção de nutrientes podem ser devidos a interferências nos carregadores específicos de íons, alterações no balaço de cargas no citossol ou modificações na fluidez e permeabilidade da membrana, como resultado da interação entre as
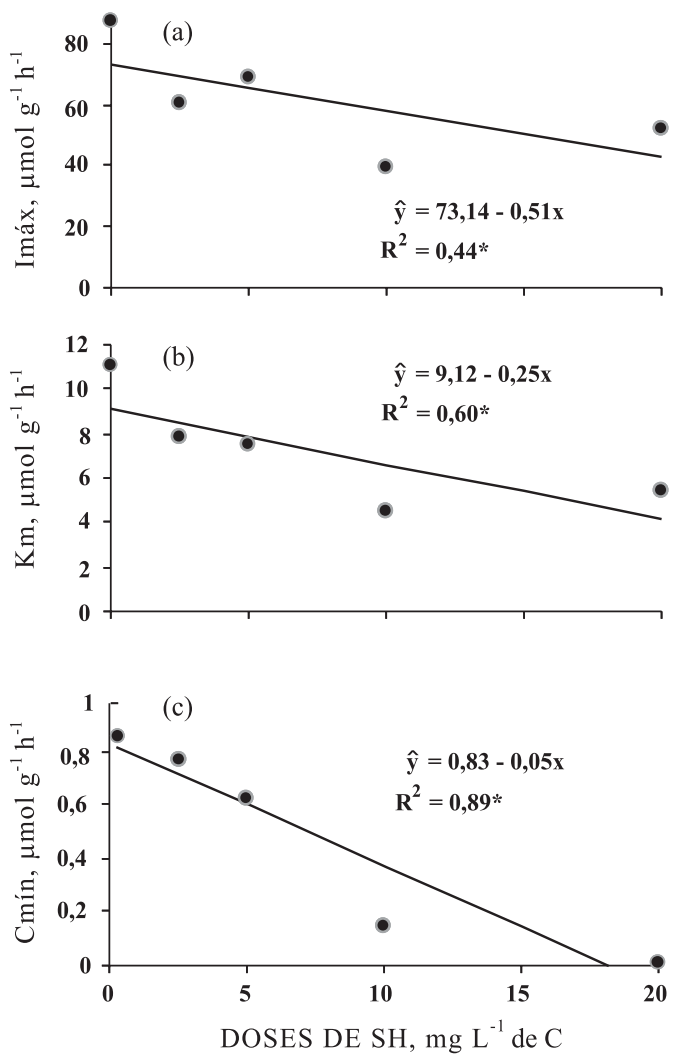

Figura 3. Parâmetros cinéticos de absorção de K de plantas de feijão, aos 28 dias, em resposta a doses de substâncias húmicas (SH). a) Imáx - Influxo máximo; b) $\mathrm{Km}$ - concentração de $\mathrm{K}$ na qual se atingiu a metade do Imáx; c) Cmín concentração mínima de $K$ na solução para absorção $(n=3)$. * significativo a $5 \%$. 
moléculas húmicas e a matriz lipídica da membrana plasmática (Samson \& Visser, 1989). Além disso, outros trabalhos evidenciaram que bombas de prótons membranares estavam envolvidas na absorção de nutrientes através da interação entre substância húmica de baixo peso molecular e ATPase de membrana plasmática, que, em certos casos, estimulou sua atividade (Nardi et al., 1991; Varanini et al., 1993; Pinton et al., 1999; Canellas \& Façanha, 2004) e, em outros, a inibiu (Nardi et al., 2000b; Canellas \& Santos, 2005), sendo tais efeitos relacionados com diferenças nas concentrações e na natureza das substâncias húmicas testadas.

Os valores de Imáx, Km e Cmín (Figura 3) colocados na equação de Michaelis - Menten, modificada por Claassen \& Barber (1974), que descreve a absorção de um íon em função de sua concentração na solução, originaram as curvas de absorção de $K$ (Figura 4).

Em concentrações de $\mathrm{K}$ menores que $10 \mu \mathrm{mol} \mathrm{L}^{-1}$, praticamente não houve diferença entre as doses de substâncias húmicas $(\mathrm{p}>0,05)$ na taxa de absorção de K. Acima deste valor, verificou-se redução na taxa de absorção com o aumento das doses de substâncias húmicas, sendo mais intensa na dose de $10 \mathrm{mg} \mathrm{L}^{-1} \mathrm{de}$ C. A sequência de decréscimo, entre os tratamentos, na taxa de absorção seguiu a mesma tendência dos valores encontrados para o Imáx, evidenciando que este foi o parâmetro determinante na taxa de absorção de K, apesar dos decréscimos observados no Cmín e $\mathrm{Km}$. Este efeito das substâncias húmicas significa que, para uma mesma concentração de $\mathrm{K}$, por exemplo $50 \mu \mathrm{mol} \mathrm{L} \mathrm{L}^{-1}$, a diminuição do influxo em relação ao tratamento sem substâncias húmicas foi de $27 \%$ na dose de $2,5 \mathrm{mg} \mathrm{L}^{-1}$ de C, $16 \%$ na dose de $5,0 \mathrm{mg} \mathrm{L}^{-1}$ de C, $49 \%$ na dose de $10 \mathrm{mg} \mathrm{L}^{-1}$ de Ce $33 \%$ na última dose testada (20 $\mathrm{mg} \mathrm{L}^{-1}$ de $\mathrm{C}$ ).

Esses resultados se opõem aos encontrados por Costa (2001), que observou maior absorção de K nos tratamentos que receberam substâncias húmicas de

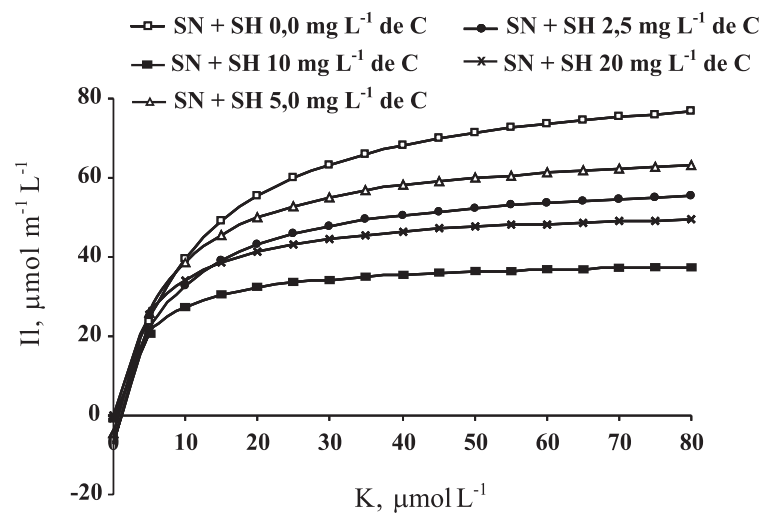

Figura 4. Taxa de absorção (Il) de $\mathrm{K}^{+}$por plantas de feijão em função da concentração externa de $K$ e de níveis de substâncias húmicas (SH) em solução nutritiva ( $\mathrm{SN})$. vermicomposto comercial, efeito que foi atribuído à mudança no balanço de cargas dentro da célula, pressupondo que moléculas de $\mathrm{SH}$, ou parte destas, com caráter predominantemente aniônico foram absorvidas, aumentando o número de cargas negativas no citoplasma, favorecendo a absorção de cátions. Segundo Cacco et al. (2000), frações húmicas de baixo peso molecular aumentaram a taxa de absorção de nitrato, enquanto resultado oposto foi evidenciado para frações húmicas de alto peso molecular. Neste trabalho, as substâncias húmicas solúveis do carvão mineral eram compostas, predominantemente, pela fração ácido húmico de maior peso molecular, ao contrário da SH de vermicomposto utilizada por Costa (2001), em que predominava a fração ácido fúlvico, mais leve. Diferenças na proporção de ácidos húmicos e fúlvicos, assim como na origem das substâncias húmicas e também na espécie vegetal utilizada nos diferentes trabalhos, possivelmente explicariam as grandes variações e discordâncias encontradas, o que dificulta a comparação dos resultados.

\section{CONCLUSÕES}

1. As substâncias húmicas extraídas de carvão mineral promovem o crescimento da parte aérea e das raízes do feijão.

2. As substâncias húmicas extraídas de carvão mineral reduziram os parâmetros cinéticos de absorção de K, Imáx, Cmín e Km, com consequente redução da taxa de absorção de $\mathrm{K}$.

\section{LITERATURA CITADA}

ANGHINONI, I.; VOLKART, C.R.; FATTORE, N. \& ERNANI, P.R. Morfologia de raízes e cinética da absorção de nutrientes em diversas espécies e cultivares de plantas. R. Bras. Ci. Solo, 13:335-361, 1989.

BARBER, S.A. Soil nutrient bioavailability: A mechanistic approach. 2.ed. New York, J. Wiley, 1995. 414p.

CACCO, G.; ATTINÀ, E.; GELSOMINO, A. \& SIDARI, M. Effect of nitrate and humic substances of different molecular size on kinetic parameters of nitrate uptake in wheat seedlings. J. Plant Nutr. Soil Sci., 163:313-320, 2000.

CLAASSEN, N. \& BARBER, S.A. A method for characterizing the relation between nutrient concentration and flux into root of intact plants. Plant Physiol., 54:564-568, 1974.

CANELLAS, L.C. \& FAÇANHA, A.R. Relationship between natures of soil humifield fractions and their bioactivity. Pesq. Agropec. Bras., 39:233-240, 2004.

CANELLAS, L.C. \& SANTOS, G.A. Humosfera: Tratado preliminar sobre a química das substâncias húmicas. Campos dos Goytacazes, 2005. 309p. 
COMISSÃO DE QUÍMICA E FERTILIDADE DO SOLO CQFSRS/SC. Manual de adubação e de calagem para os Estados do RS e SC. 10.ed. Porto Alegre, Sociedade Brasileira de Ciência do solo - Núcleo Regional Sul, 2004. 394p.

COSTA, C.N. Efeito das substâncias húmicas no desenvolvimento radicular da cebola, Allium cepa L., e na cinética de absorção de fósforo e potássio. Pelotas, Universidade Federal de Pelotas, 2001. 51p. (Tese de Mestrado).

DICK, D.P.; DICK, Y.P.; DA SILVA, L.F.; ESSIG, C. \& ZORTEA, R.B. Caracterização de produtos de decomposição de lodos orgânicos em diferentes tempos e meios de digestão. $\mathrm{R}$. Bras. Ci. Solo, 21:1-8, 1997.

DICK, D.P.; GOMES, J. \& ROSINHA, P.B. Caracterização de substâncias húmicas extraídas de solos e de lodo orgânico. R. Bras. C. Solo, 22:603-611, 1998.

FAÇANHA, A.R.; FAÇANHA, A.L.O.; OLIVARES, F.L.; GURID, F.; SANTOS, G.A.; VELLOSO, A.C.X.; RUMJANEK, V.M.; BRASIL, F.; SCHRIPSEMA, J.; BRAZ-FILHO, R.; OLIVEIRA, M.A. \& CANELLAS, L.P. Bioatividade de ácidos húmicos: Efeito sobre o desenvolvimento radicular e sobre a bomba de prótons da membrana plasmática. Pesq. Agropec. Bras., 37:13011310,2002

MACHADO, A.A. Sistema de análise estatística para Windows (WINSTAT). Pelotas, Universidade Federal de Pelotas, 2001.

NARDI, S.; CONCHERI, G.; DELL'AGNOLA, G. \& SCRIMIN, P. Nitrate uptake and ATPase activity in oat seedlings in the presence of two humic fractions. Soil Biol. Biochem., 23:833-836, 1991.

NARDI, S.; PIZZEGHELLO, D.; RENIERO, F. \& RASCIO, N. Chemical and biochemical properties of humic substances isolated from forest soils and plant growth. Soil Sci. Soc. Am. J., 64:639-645, 2000a.

NARDI, S.; PIZZEGHELLO, D.; GESSA, C.; FERRARESE, L.; TRAINOTTI, L. \& CASADORO, G. A low molecular weight humic fraction on nitrate uptake and protein synthesis in maize seedlings. Soil Biol. Biochem., 32:415$419,2000 \mathrm{~b}$.

NARDI, S.; PIZZEGHELLO, D.; MUSCOLO, A. \& VIANELLO, A. Physiological effects of humic substances on higher plants. Soil Biol. Biochem., 34:1527-1536, 2002.

PICOLLO, A. The supramolecular structure of humic substances: A novel understanding of humus chemistry and implications in soil science. Adv. Agron, 75:57-134, 2002.

PINTO, L.F.S. \& KÄMPF, N. Contaminação dos solos construídos. In: TEIXEIRA, E.C. \& PIRES, M.J.R. Meio ambiente e carvão. Impactos da exploração e utilização. Porto Alegre, FINEP/ CAPES/ PADCT/ GTM/ PUCRS/ UFSM/ FEPAN, 2002. p.69-92.

PINTON, R.; VARANINI, Z.; VIZZOTO, G. \& MAGGIONI, A. Soil humic substances affect transport properties of tonoplast vesicles isolated from oat roots. Plant Soil, 142:203-210, 1992.
PINTON, R.; CESCO, S.; IACOLETTI, G.; ASTOLFI, S. \& VARANINI, Z. Modulation of nitrate uptake by waterextractable humic substances: Involvent of root plasma membrane $\mathrm{H}^{+}$-ATPase. Plant Soil, 215:155$163,1999$.

RAYLE, D.L. \& CLELAND, R.E. The acid growth theory of auxin-induced cell elongation is alive and well. Plant Physiol., 99:1271-1274, 1992.

RODDA, M.R.C.; CANELLAS, L.P.; FAÇANHA, A.R.; ZANDONADI, D.B.; GUERRA, J.G.M.; ALMEIDA, D.L. \& SANTOS, G.A. Estímulo no crescimento e na hidrólise de ATP em raízes de alface tratadas com humatos de vermicomposto. I - Efeito da concentração. R. Bras. Ci. Solo, 30:649-656, 2006a.

RODDA, M.R.C.; CANELLAS, L.P.; FACANHA, A.R.; ZANDONADI, D.B.; GUERRA, J.G.M.; ALMEIDA, D.L. \& SANTOS, G.A. Estímulo no crescimento e na hidrólise de ATP em raízes de alface tratadas com humatos de vermicomposto. II - Efeito da fonte de vermicomposto. R. Bras. Ci. Solo, 30:657-664, 2006b.

RUIZ, H.A. Estimativa dos parâmetros cinéticos Km e Imáx por uma aproximação gráfico-matemática. R. Ceres, 32:79-84, 1985.

SAMSON, G. \& VISSER, S.A. Surface-active effect of humic acids on potato cell membrane properties. Soil Biol. Biochem., 21:343-347, 1989.

SANTOS, G.A. \& CAMARGO, F.A.O. Fundamentos da matéria orgânica do solo: Ecossistemas tropicais e subtropicais. Porto Alegre, Gênesis, 1999. 491p.

SILVA, I.R. \& MENDONÇA, E.S. Matéria orgânica do solo. In: NOVAIS, R.F.; ALVAREZ V., V.H.; BARROS, N.F.; FONTES, R.L.F.; CANTARUTTI, R.B. \& NEVES, J.C.L. Fertilidade do solo. Viçosa, MG, Sociedade Brasileira de Ciência do Solo, 2007. p.275-374.

SILVA, M.B. \& KALKREUTH, W. Petrological and geochemical characterization of Candiota coal seams, Brazil - Implication for coal facies interpretations and coal rank. Inter. J. Coal Geol., 64:217-238, 2005.

SILVA, R.M.; JABLONSKI, A.; SIEWERDT, L. \& SILVEIRA JÚNIOR, P. Crescimento da parte aérea e do sistema radicular do milho cultivado em solução nutritiva adicionada de substâncias húmicas. R. Bras. Agroci., 5:101-110, 1999.

SILVA, R.M.; JABLONSKI, A.; SIEWERDT, L. \& SILVEIRA JÚNIOR, P. Desenvolvimento das raízes de azevém cultivado em solução nutritiva completa, adicionada de substâncias húmicas, sob condições de casa de vegetação. R. Bras. Zootec., 29:101-110, 2000.

SPOSITO, G. The chemistry of soils. Oxford, Oxford University Press, 1989. 277p.

STEVENSON, J.F. Humus chemisthy, gênesis, composition, reactions. 2.ed. New York, John Wiley, 1994. 496p. 
TAN, K.H. Colloidal chemistry of organic soil constituents. In: TAN, K.H. Principles of soil chemistry. New York, Marcel Dekker, 1998. p.177-258.

TEDESCO, M.J.; GIANELLO, C.; BISSANI, C.A.; BOHNEN, H. \& VOLKWEISS, S.J. Análise de solo, plantas e outros materiais. 2.ed. Porto Alegre, Universidade Federal do Rio Grande do Sul, 1995. 174p

TENNANT, A.A. Test of modified line intersect method of estimating root length. J. Appl. Ecol., 63:995-1001, 1975.
VARANINI, Z.; PINTON, R.; DE BIASI, M.G.; ASTOLFI, S. \& MAGGIONI, A. Low molecular weight humic substances stimulated $\mathrm{H}^{+}$-ATPase activity of plasma membrane vesicles isolated from oat (Avena sativa L.) roots. Plant Soil, 153:61-69, 1993.

VAUGHAN, D.; MALCOM, R.E. \& ORD, B.G. Influence of humic substances on biochemical processes in plants. In: VAUGHAN, D. \& MALCOM, R.E. Soil organic matter and biological activit. Dordrecht, Martinus Nijhoff/Junk W, 1985. p.77-108. 
